\title{
Cytologic, histologic and molecular findings of papillary thyroid carcinoma variants, one institution's experience
}

\author{
Nadja K Falk*1, Swarnamala Ratnayaka ${ }^{1}$, Andrew B. Sholl ${ }^{2}$, Krzysztof Moroz ${ }^{1}$, Tatyana Kalinicheva ${ }^{3}$ \\ ${ }^{1}$ Department of Pathology and Laboratory Medicine, Tulane University School of Medicine, New Orleans, LA, United States \\ ${ }^{2}$ Ochsner Department of Pathology, New Orleans, LA, United States \\ ${ }^{3}$ Thibodaux Regional Medical Center, Thibodaux, LA, United States
}

Received: March 27, 2019

DOI: $10.5430 /$ jst.v9n2p32
Accepted: July 23, 2019

Online Published: July 30, 2019

\begin{abstract}
Papillary thyroid carcinoma (PTC) has two major types, classic (PTCC) and follicular variant (FVPTC), which correlate with molecular findings and have varying clinical implications. We assessed the cytologic findings and subsequent surgical pathology findings with the molecular mutations in these two groups, including microcarcinomas. Fourty-four patients with PTC resections over a one-year period were retrospectively examined in conjunction with previous cytologic diagnoses. BRAF, NRAS and TERT promoter mutations for the resected specimens were analyzed. Correlation with previous cytology in regard to molecular mutations and tumor size (microcarcinoma) were made. Significantly more BRAF V600E mutations were seen with PTCC, whereas significantly more NRAS mutations were seen with FVPTC. TERT mutations were only seen with PTCC. Molecular studies for thyroid carcninomas are becoming increasingly more common and influence treatment and patient prognosis. BRAF and or TERT mutations are associated with a worse prognosis. NRAS mutations associated with FVPTC and may lead to milder cytologic changes compared to the BRAF- and TERT-driven PTCC.
\end{abstract}

Key Words: Papillary thyroid carcinoma, follicular variant, BRAF, NRAS, TERT

\section{INTRODUCTION}

Thyroid carcinoma (TC) is the most common endocrine malignancy. ${ }^{[1,2]}$ More than $80 \%$ of thyroid carcinomas are PTC, and its incidence is steadily increasing at a rate of $3 \%$ per year. ${ }^{[3]}$ The age-standardized incidence rate of thyroid cancer per year in developed countries is 6.62 for men and 20.8 per women per 100,000 . PTC accounts for $1.5 \%$ of all cancers in the United States (US). Approximately $5 \%$ of US individuals fifty years or older have palpable thyroid nodules, however only $5 \%-15 \%$ of thyroid nodules are malignant; and the lifetime risk of TC diagnosis in the US is $1.2 \% .^{[4-6]} \mathrm{TC}$ occurs 2-3 times more often in women and is the fifth most common malignancy diagnosed in women. Since the 1970s, ultrasound-guided fine needle aspirations (US-FNA) have been performed for the initial diagnosis of thyroid nodules and for management triage. ${ }^{[7-9]}$

Many PTC subtypes exist, including PTCC, FVPTC, solid/trabecular, tall cell, columnar cell, diffuse sclerosing, hobnail, and cribiriform-morular. ${ }^{[10]}$ Most PTC cases are PTCC or FVPTC histologic sub-types, 55\%-65\% and 23\%$41 \%$ respectively. Histologic features of PTCC include nuclear grooves, intranuclear inclusions, and papillary architecture. FVPTC was originally described by Crile and Hazard

*Correspondence: Nadja Falk; Email: nfalk@salud.unm.edu; Address: Department of Pathology, University of New Mexico, Albuquerque, NM 87131-0001, United States. 
in 1953 and subsequently categorized by Lindsay et al. and Chem and Rosai. ${ }^{[10-12]}$ FVPTC has a predominantly follicular pattern while retaining the PTC nuclear features and may only have focal papillary architecture. ${ }^{[13,14]}$ US-FNA has a low sensitivity for detecting FVPTC; 45\%-77\% of FVPTC are classified as atypia of undetermined significance or follicular lesion of undetermined significance and only $7 \%-48 \%$ are diagnosed as malignant. ${ }^{[14-17]}$ Papillary microcarcinoma (PTC-M) is defined by the World Health Organization as a papillary thyroid cancer measuring $10 \mathrm{~mm}$ or less in diameter. PTC-M is usually indolent, with mortality less than $1 \%$ with a locoregional recurrence of approximately $5 \% .^{[18]}$

PTC genetic changes commonly activate the MAPK pathway and are dominated by driving somatic mutations in BRAF and RAS oncogenes. In addition to PTC, somatic mutations BRAF genes have been found in multiple other cancers, including non-Hodgkin lymphoma, colorectal cancer, malignant melanoma, and non-small cell lung carcinoma. BRAF is a serine-threonine kinase that is an activator downstream of the RAS oncogene in the pathway. ${ }^{[19]}$ BRAF V600E mutation makes up the majority of BRAF mutations in PTC, in which a point mutation at codon 600 leads to a valine substitution to glutamic acid. ${ }^{[4]}$ This mutation increases BRAF kinase activity through increasing ERK1/2 phosphorylation and leads to increased cell proliferation, differentiation, survival, tumorigenesis and promotion of epithelial-mesenchymal transition. The average BRAF V600E mutation frequency is $48 \%$ in PTCC and $10 \%$ in FVPTC. ${ }^{[2,12,20,21]}$ BRAF V600E mutation is $>99 \%$ specific for the diagnosis of TC. ${ }^{[22]}$

NRAS mutations are seen in approximately $40 \%$ of FVPTC and only rarely in PTCC. ${ }^{[3,4,7,23]}$ NRAS is a member of the RAS family of GTPase and plays an important role as a mediator of cellular growth signals generated by upstream receptor tyrosine kinases. In addition to PTC, activating mutations of NRAS are found in various types of cancers, including $15 \%-25 \%$ of melanomas, $3 \%-5 \%$ of colorectal cancers, and $5 \%-10 \%$ of hepatocellular carcinomas. The most common NRAS mutations in PTC involve codon 61 (Q61R or Q61K). ${ }^{[20]}$ These point mutations decrease intrinsic GTPase activity, which increases activation of the MAPK and PI3/AKT signaling pathways [24]. RAS mutations are seen in $15 \%-20 \%$ of PTC, $40 \%-50 \%$ of follicular carcinoma, and $20 \%-40 \%$ of follicular adenomas, and $26 \%-45 \%$ of FVPTC. ${ }^{[15,25,26]}$

In 2013, TERT gene promoter mutations were detected in thyroid carcinoma. ${ }^{[8]}$ TERT is an enzyme involved in telomere elongation. TERT overexpression is caused by a mutation in its promoter region which promotes tumor cell sur-

Published by Sciedu Press vival. The TERT promoter mutations cluster mainly in two hotspots, c.1-124C > T(C228T) and c.1-146C > T(C250T), which are transition mutations corresponding to nucleotides -124 and -146 upstream of the initiation codon ATG, respectively. TERT mutations have been described in TC, central nervous system tumors, bladder cancer, hepatocellular carcinoma, and melanoma ( $71 \%$ of patients). TERT gene promoter region mutations are reported in $7 \%-22 \%$ of PTC and follicular carcinomas and $29 \%-95 \%$ of dedifferentiated thyroid cancers. Of these, TERT promoter mutations are seen in about $30 \%$ of tall cell variant PTC and in approximately $40 \%$ of poorly differentiated and anaplastic thyroid carcinomas, which are clinically more aggressive. ${ }^{[7]}$ C228T TERT promoter mutation has been associated BRAF V600E mutation in aggressive thyroid cancer. ${ }^{[5,7,27-29]}$ TERT mutations are uncommon in PTC-M. ${ }^{[17,30,31]}$

\section{MethodS}

Forty-four patients, thirty-six females and eight males, with PTC resections over a one-year period were retrospectively studied (see Table 1). The resections, some of which included multifocal carcinoma, included sixty-two PTC foci, of which thirty-three were PTCC and twenty-nine were FVPTC. 55\% of these PTC foci had been previously aspirated and evaluated cytologically. The resected PTCC and FVPTC foci were analyzed for BRAF, NRAS and TERT mutations. A two-sample t-test between percent was used to determine significance of molecular alterations between the PTCC and FVPTC groups.

Table 1. Demographic information

\begin{tabular}{|l|l|}
\hline Age & 26-78 years old (mean = 50 years) \\
\hline Gender distribution & $\begin{array}{l}\text { Females: 36 (82\%) } \\
\text { Males: 8 (18\%) }\end{array}$ \\
\hline $\begin{array}{l}\text { Number of resected PTC } \\
\text { foci evaluated }\end{array}$ & $\begin{array}{l}\text { 62 PTC foci, including: } \\
\text { PTCC: 33/62 (53\%) } \\
\text { FVPTC: 29/62 (47\%) }\end{array}$ \\
\hline $\begin{array}{l}\text { Fine needle aspiration } \\
\text { cytology }\end{array}$ & 34 (55\%) foci \\
\hline
\end{tabular}

Note. PTC - Papillary thyroid carcinoma; PTCC - Papillary thyroid carcinoma, classical type; FVPTC - Papillary thyroid carcinoma, follicular variant

BRAF and NRAS real time polymerase chain reaction (RTPCR) testing was performed in the Tulane University Molecular Pathology Laboratory. A designated pathologist identified the presence of at least $20 \%$ tumor cells in hematoxylin and eosin-stained slides prepared from formalin-fixed, paraffinembedded tissue sections. DNA was isolated using Qiagen EZ1 tissue kit (Qiagen, CA). Mutated BRAF or NRAS gene was detected using a validated BRAF or NRAS mutation kits (EntroGen, CA) and RT-PCR methodologies (Light Cycler 480, Roche Applied Science, IN) with an analyti- 
cal sensitivity of $1 \%-5 \%$ mutant in a background of wildtype genomic DNA. The following BRAF mutations were tested: V600E (Val600Glu), V600K (Val600Lys), V600D (Val600Asp), V600R (Val600Arg), and V600M (Val600Met) found in codon 600. Somatic mutations located in codons 12,13 , and 61 of the NRAS gene were tested.

TERT Promoter Mutation by next generation sequencing (NGS) (c.1-124C > T (C2228T) and c.1-146C > T (C250T)) analysis was performed at University of Pittsburgh Medical Center, where a molecular pathologist determined lesional cell adequacy for microdissection on hematoxylin and eosinstained slides. Torrent suite Software v5.2.2 was used for data analysis. The analytical sensitivity for TERT variant detection at $>3 \%-5 \%$ mutant allele frequency was $>99.9 \%$. The analytical specificity was $>99 \%$ and the minimal required sequencing depth was 500x.

\section{RESULTS}

Significantly more BRAF V600E mutations were seen in PTCC foci versus FVPTC foci, $85 \%$ versus $18 \%$ respec- tively. Conversely, more NRAS Q61R or Q61K mutations were seen in FVPTC foci versus PTCC foci, $29 \%$ versus $4 \%$ respectively. TERT C228T mutation was seen in 33\% of PTCC foci and not found in FVPTC foci (see Table 2).

Fourteen PTCC foci, of which six were histologically diagnosed as microcarcinoma upon resection, had had previous ultrasound-guided fine needle aspirations and cytologic diagnoses. Ten FVPTC foci, of which three were histologically diagnosed as microcarcinoma upon resection, had had previous ultrasound-guided fine needle aspirations and cytologic diagnoses. The macrocarcinomas (more than $1.0 \mathrm{~cm}$ in size) were more often categorized in higher Bethesda categories, including suspicious for follicular neoplasm or suspicious for malignancy, whereas the microcarcinomas were more often categorized in lower Bethesda categories, including benign or atypical. Upon resection, the similar trend of BRAF mutation being present in more PTCC versus FVPTC and NRAS mutations being present in more FVPTC versus PTCC was seen. TERT mutation was seen only in PTCC (see Table 3).

Table 2. Frequency of BRAF, NRAS and TERT mutations identified in resected specimens of PTC, classical type and follicular variant

\begin{tabular}{llll}
\hline Mutation & PTCC & FVPTC & Two-sample $\boldsymbol{t}$-test between percent \\
\hline BRAF V600E c.1799T>A & $22 / 26(85 \%)$ & $4 / 22(18 \%)$ & $p=.00005^{*}$ \\
NRAS Q61R or Q61K & $1 / 26(4 \%)$ & $7 / 24(29 \%)$ & $p=.0199 *$ \\
TERT C228T & $3 / 9(33 \%)$ & $0 / 9(0 \%)$ & $p=.0776$ \\
\hline *p-value is less & & &
\end{tabular}

Table 3. Preceding cytologic aspiration diagnoses for resected foci of PTC, classical type and follicular variant, with correlation to BRAF V600E, NRAS (Q61R or Q61K) and TERT C228T mutations.

\begin{tabular}{|c|c|c|c|c|}
\hline PTC types (Total \# of foci) & $\begin{array}{l}\text { Bethesda II* } \\
\text { N }(\%)\end{array}$ & 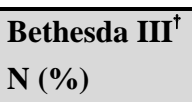 & 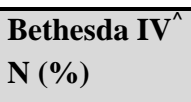 & $\begin{array}{l}\text { Bethesda V \& VI } \\
\mathbf{N}(\%)\end{array}$ \\
\hline PTCC (14) & $2(14 \%)$ & $1(7 \%)$ & $0(0 \%)$ & $11(79 \%)$ \\
\hline PTCC-M (6) & $2(33.3 \%)$ & $2(33.3 \%)$ & $0(0 \%)$ & $2(33.3 \%)$ \\
\hline BRAF mutation (16) & $3(19 \%)$ & $3(19 \%)$ & $0(0 \%)$ & $10(62 \%)$ \\
\hline BRAF wild-type (4) & $1(25 \%)$ & $0(0 \%)$ & $0(0 \%)$ & $3(75 \%)$ \\
\hline NRAS mutation (0) & $0(0 \%)$ & $0(0 \%)$ & $0(0 \%)$ & $0(0 \%)$ \\
\hline NRAS wild-type (20) & $4(20 \%)$ & $3(15 \%)$ & $0(0 \%)$ & $13(65 \%)$ \\
\hline TERT mutation (1) & $0(0 \%)$ & $0(0 \%)$ & $0(0 \%)$ & $1(100 \%)$ \\
\hline TERT wild-type (5) & $1(20 \%)$ & $1(20 \%)$ & $0(0 \%)$ & $3(60 \%)$ \\
\hline FVPTC (10) & $2(20 \%)$ & $4(40 \%)$ & $0(0 \%)$ & $4(40 \%)$ \\
\hline FVPTC-M (3) & $1(33.3 \%)$ & $1(33.3 \%)$ & $1(33.3 \%)$ & $0(0 \%)$ \\
\hline BRAF mutation (4) & $1(25 \%)$ & $1(25 \%)$ & $1(25 \%)$ & $1(25 \%)$ \\
\hline BRAF wild-type (9) & $2(22 \%)$ & $4(44 \%)$ & $0(0 \%)$ & $3(33 \%)$ \\
\hline NRAS mutation (6) & $1(17 \%)$ & $3(50 \%)$ & $0(0 \%)$ & $2(33 \%)$ \\
\hline NRAS wild-type (7) & $2(28.6 \%)$ & $2(28.6 \%)$ & $1(14.3 \%)$ & $2(28.6 \%)$ \\
\hline TERT mutation (0) & $0(0 \%)$ & $0(0 \%)$ & $0(0 \%)$ & $0(0 \%)$ \\
\hline TERT wild-type (5) & $1(20 \%)$ & $2(40 \%)$ & $0(0 \%)$ & $2(40 \%)$ \\
\hline
\end{tabular}

Note. PTCC - Papillary thyroid carcinoma, classical type; PTCC-M - Papillary thyroid microcarcinoma, classical type; FVPTC - Papillary thyroid carcinoma, follicular variant; FVPTC-M - Papillary thyroid microcarcinoma, follicular variant; N - Number; ${ }^{*}$ Benign; $†$ Atypia of undetermined significance / Follicular lesion of undetermined

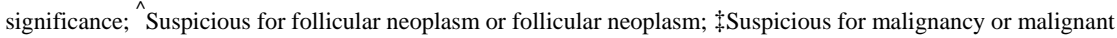




\section{Discussion}

PTC has a good prognosis with up to $95 \%$ survival after ten years. PTCC is generally more aggressive with more metastatic potential than FVPTC. FVPTC patients tend to have a lower prevalence of extrathyroidal extension and lymph node metastasis. PTC treatment usually includes surgery followed by radioactive iodine. Up to $20 \%$ of patients, however, relapse after initial treatment, and 5\%-10\% will metastasize. Poor prognostic features include older age, male sex, large size, and extrathyroidal extension. ${ }^{[32]} 5 \%$ $10 \%$ of the patients with relapsed PTC do not respond to conventional therapies. Therefore, early identification of high-risk patients is paramount. ${ }^{[6,10,12,33]}$

BRAF mutations are associated with a poor prognosis and tumor aggressiveness (extrathyroidal extension, lymph node metastasis, radioiodine treatment failure, and recurrence) and may be associated with the tumor being more often bilateral. ${ }^{[3,34]}$ Without other coexisting genetic alterations, RAS mutated PTC lacks an aggressive behavior. ${ }^{[35]}$ TERT promoter mutations correlate with aggressive clinicopathological features and poor outcomes. ${ }^{[36]}$ Concomitant BRAF and TERT mutated tumors have particularly high-risk clinicopathological characteristics and increased recurrence rates. BRAF V600E-activated MAP kinase pathway upregulates ETS transcription factors, which in turn increase the expression of TERT by attaching to the binding site in the TERT promoter created by the $\mathrm{C} 228 \mathrm{~T}$ or $\mathrm{C} 250 \mathrm{~T}$ mutation. Patients with BRAF and TERT mutations recur in approximately $70 \%$ of cases, whereas patients with only one of these mutations recur in approximately $9 \%$ of cases. ${ }^{[7,27,30,38-44]}$

The MAPK pathway is the predominant therapy target in advanced thyroid carcinomas. ${ }^{[4]}$ Molecular markers may influence targeted therapy for advanced disease, and systemic therapy may be considered in the following circumstances: progressive, locally recurrent, advanced, metastatic, or surgically unresectable disease or tumors not amenable to radioactive iodine. Lenvatinib, sorafenib, sunitinib, axitinib, everolimus, vandetinib, cabozantinib, and pazopanib are examples of kinase inhibitors. Bleeding, hypertension, stroke and liver toxicity are possible side effects, and most are alleviated by discontinuing the systemic therapy. ${ }^{[1]}$

\section{Conclusion}

TC molecular mutation studies are commonly performed, not only on surgically resected specimens but also on cytologic samples. Diagnosing FVPTC is difficult cytologically; however, the presence of NRAS mutations and lack of BRAF and or TERT mutations may help clinicians to favor this diagnosis. The sheer size of microcarcinomas may hinder accurate cytologic diagnoses due to possible sampling error. Overall, BRAF and TERT individually portend a worse prognosis in PTC; however, concomitant BRAF and TERT mutations may indicate an even worse prognosis for the patient.

\section{CONFLICTS OF INTEREST Disclosure}

The author declares no conflict of interest

\section{REFERENCES}

[1] Haddad RI, Nasr C, Bischoff L, Busaidy NL, Byrd D, et al. NCCN guidelines insights: Thyroid carcinoma, version 2.2018. J Natl Compr Canc Netw. 2018 Dec; 16(12):1429-1440. PMid:30545990. https://doi.org/10.6004/jnccn.2018.0089

[2] Bandoh N, Akehane T, Goto T, et al. Targeted next-generation sequencing of cancer-related genes in thyroid carcinoma: A single institution's experience. Oncol Lett. 2018 Dec; 16(6):7278-7286. PMid:30546467. https ://doi.org/10.3892/ol.2018.9538

[3] Canadas GM, Becerra MP, Casares AM, et al. Relevance of BRAF and NRAS mutations in the primary tumor and metastases of papillary thyroid carcinoma. Head Neck. 2016 Dec; 38(12):1772-1779. PMid:27299298. https://doi.org/10.1002/hed.24517

[4] Chen H, Luthra R, Routbort MJ, Patel KP, Cabanillas ME, et al. Molecular profile of advanced thyroid carcinomas by nextgeneration sequencing: Characterizing tumors beyond diagnosis for targeted therapy. Mol Cancer Ther. 2018 Jul; 17(7):15751584. PMid:29695638. https://doi org/10.1158/1535-7163. MCT-17-0871

[5] Fakhruddin N, Jabbour M, Novy M, et al. BRAF and NRAS mutations in papillary thyroid carcinoma and concordance in BRAF mutations between primary and corresponding lymph node metas- tases. Sci Rep. 2017 Jul; 7(1):4666. PMid:28680105. https : //doi . org/10.1038/s41598-017-04948-3

[6] Penna GC, Vaisman F, Vaisman M. Molecular markers involved in tumorigenesis of thyroid carcinoma: Focus on aggressive histiotypes. Cytogenet Genome Res. 2016; 150(3-4):194-207. PMid:28231576. https ://doi.org/10.1159/000456576

[7] Kure S, Wada R, Naito Z. Relationship between genetic alterations and clinicopathological characteristics of papillary thyroid carcinoma. Med Mol Morphol. 2019 Feb. PMid:30788603. https : //doi.org/10.1007/s00795-019-00217-6

[8] Valvo V, Nucera C. Coding molecular determinants of thyroid cancer development and progression. Endocrinol Metab Clin North Am. 2019 Mar; 48(1):37-59. PMid:30717910. https : //doi .org/10.1 016/j.ecl.2018.10.003

[9] Patel SG, Carty SE, McCoy KL, et al. Preoperative detection of RAS mutation may guide extent of thyroidectomy. Surgery. 2017 Jan; 161(1):168-175. PMid:27863786. https ://doi .org/10.1016/j. surg. 2016.04.054

[10] Yang J, Gong Y, Yan S, et al. Comparison of the clinicopathological behavior of the follicular variant of papillary thyroid carcinoma and classical papillary thyroid carcinoma: A systematic review and meta- 
analysis. Mol Clin Oncol. 2015 Jul; 3(4):753-764. PMid:26171175. https://doi.org/10.3892/mco.2015.540

[11] Chem KT, Rosai J. Follicular variant of thyroid papillary carcinoma: a clinicopathologic study of six cases. Am J Surg Pathol. 1977 Jun; 1(2):123-30. https://doi.org/10.1097/00000478 -197706000-00003

[12] Henke LE, Pfeifer JD, Baranski TJ, et al. Long-term outcomes of follicular variant vs classic papillary thyroid carcinoma. Endocr Connect. 2018 Dec; 7:12):1226-1235. PMid:30352402. https : //doi.org/10.1530/EC-18-0264

[13] Guney G, Tezel GG, Kosemehmetoglu K, et al. Molecular features of follicular variant papillary carcinoma of thyroid: comparison of areas with or without classical nuclear features. Endocr Pathol. 2014 Sep; 25(3):241-7. PMid:24277231. https : //doi.org/10.1007/ s12022-013-9275-6

[14] Lee SR, Jung CK, Kim TE, et al. Molecular genotyping of follicular variant of papillary thyroid carcinoma correlates with diagnostic category of fine needle aspiration cytology: values of RAS mutation testing. Thyroid. 2013 Nov; 23(11):1416-22. PMid:23590130. https://doi.org/10.1089/thy.2012.0640

[15] Hwang TS, Kim WY, Han HS, et al. Preoperative RAS mutational analysis is of great value in predicting follicular variant of papillary thyroid carcinoma. Biomed Res Int. 2015; 2015:697068. PMid:25648502. https://doi.org/10.1155/2015/697068

[16] Kim MJ, Won JK, Jung KC, et al. Clinical characteristics of subtypes of follicular variant papillary thyroid carcinoma. Thyroid. $2018 \mathrm{Mar}$; 28(3):311-318. PMid:29343212. https://doi.org/10.1089/th y. 2016.0671

[17] de Biase, Gandolfi G, Ragazzi M, et al. TERT promoter mutations in papillary thyroid microcarcinomas. Thyroid. 2015 Sep; 25(9):1031-9. PMid:26148423. https://doi.org/10.1089/thy.2015.0101

[18] Rodrigues AC, Penna G, Rodrigues E, et al. The genetics of papillary microcarcinomas of the thyroid: Diagnostic and prognostic implications. Curr Genomics. 2017 Jun; 18(3):244-254. PMid:28659720. https://doi.org/10.2174/1389202918666170105094459

[19] Adeniran AJ, Hui P. Best practice of BRAF V600E mutation testing for the diagnosis and management of thyroid cancers. Expert Rev Endocrinol Metab. 2014 Nov; 9(6):571-577. PMid:30736195. https://doi.org/10.1586/17446651.2014.951635

[20] Melo M, Gaspar da Rocha A, Batista R, et al. TERT, BRAF, and NRAS in primary thyroid cancer and metastatic disease. J Clin Endocrinol Metab. 2017 Jun; 102(6):1898-1907. PMid:28323937. https://doi.org/10.1210/jc. 2016-2785

[21] Kowalska A, Walczyk A, Kowalik A, et al. Increase in papillary thyroid cancer incidence is accompanied by changes in the frequency of the BRAFV600E mutation: A single-institution study. Thyroid. 2016; 26(4):543-551. PMid:26889698. https ://doi.org/10.1089/th $\mathrm{y} \cdot 2015.0352$

[22] Poller DN, Glaysher S. Molecular pathology and thyroid FNA. Cytopathology. 2017 Dec; 28(6):475-481. PMid:29165888. https : //doi.org/10.1111/cyt. 12492

[23] Tallini G, Tuttle RM, Ghossein RA. The history of the follicular variant of papillary thyroid carcinoma. J Clin Endocrinol Metab. 2017 Jan;102(1):15-22. PMid:25148236. https://doi:10.1210/jc. 2 014-2611

[24] An JH, Song KH, Kim SK, et al. Ras mutations in indeterminate thyroid nodules are predictive of the follicular variant of papillary thyroid carcinoma. Clin Endocrinol (Oxf). 2015 May; 82(5):760-6. PMid:25109485. https://doi.org/10.1111/cen. 12579

[25] Crescenzi A, Fulciniti F, Bongiovanni M, et al. Detecting N-RAS Q61R mutated thyroid neoplasias by immunohistochemistry. Endocr
Pathol. 2017 Mar; 28(1):71-74. PMid:28064410. https ://doi .or $\mathrm{g} / 10.1007 / \mathrm{s} 12022-016-9466-z$

[26] Rivera M, Ricarte FJ, Knauf J, et al. Molecular genotyping of papillary thyroid carcinoma follicular variant according to its histological subtypes (encapsulated vs infiltrative) reveals distinct BRAF and RAS mutation patterns. Mod Pathol. 2010 Sep; 23(9):1191-200. PMid:20526288. https ://doi.org/10.1038/modpathol. 2010 .112

[27] Vuong HG, Duong UN, Altibi AM, Ngo HT, Pham TQ, et al. A meta-analysis of prognostic roles of molecular markers in papillary thyroid carcinoma. Endocr Connect. 2017 Apr; 6(3):R8-R17. PMid:28219937. https ://doi.org/10.1530/EC-17-0010

[28] Proietti A, Sartori C, Macerola E, et al. Low frequency of TERT promoter mutations in a series of well-differentiated follicularpatterned thyroid neoplasms. Virchows Arch. 2017 Dec; 471(6):769773. PMid:28975450. https://doi.org/10.1007/s00428-017 $-2236-6$

[29] Alzahrani AS, Alsaadi R, Murugan AK, et al. TERT promoter mutations in thyroid cancer. Horm Cancer. 2016 Jun; 7(3):165-77. PMid:26902827 https : //doi.org/10.1007/s12672-016-025 6-3

[30] Kim TH, Kim YE, Ahn S, et al. TERT promoter mutations and longterm survival in patients with thyroid cancer. Endocr Relat Cancer. 2016 Oct; 23(10):813-23. PMid:27528624. https ://doi .org/10 .1530/ERC-16-0219

[31] Kim TH, Ki CS, Kim HS, et al. Refining dynamic risk stratification and prognostic groups for differentiated thyroid cancer with TERT promoter mutations. J Clin Endocrinol Metab. 2017 May; 102(5):1757-1764. PMid:28323925. https ://doi.org/10.1210/ jc. 2016-3434

[32] Adeniran AJ, Zhu Z, Gnadhi M, et al. Correlation between genetic alterations and microscopic features, clinical manifestations, and prognostic characteristics of thyroid papillary carcinomas. Am J Surg Pathol. 2006 Feb; 30(2):216-22. PMid:16434896. https : //doi.org/10.1097/01.pas.0000176432.73455.1b

[33] Bernaud C, Descotes F, Decaussin PM, et al. TERT promoter mutations identify a high-risk group in metastasis-free advanced thyroid carcinoma. Eur J Cancer. 2019 Feb; 108:41-49. PMid:30648628. https://doi.org/10.1016/j.ejca.2018.12.003

[34] Liu Z, Lv T, Xie C, et al. BRAF V600E gene mutation is associated with bilateral malignancy of papillary thyroid cancer. Am J Med Sci. 2018 Aug; 356(2):130-134. PMid:30219154. https : //doi.org/10.1016/j.amjms.2018.04.012

[35] Insilla AC, Proietti A, Borrelli N, et al. TERT promoter mutations and their correlation with BRAF and NRAS mutations in a consecutive cohort of 145 thyroid cancer cases. Oncol Lett. 2018 Mar; 15(3):2763-2770. https ://doi .org/10.3892/ol.2017.7675

[36] Yin DT, Yu K, Lu RQ, et al. Clinicopathological significance of TERT promoter mutation in papillary thyroid carcinomas: a systematic review and meta-analysis. Clin Endocrinol (Oxf). 2016 Aug; 85(2):299 305. PMid:26732020 https ://doi.org/10.1111/cen.13017

[37] Ren H, Shen Y, Hu D, et al. Co-existence of BRAFV600E and TERT promoter mutations in papillary thyroid carcinoma is associated with tumor aggressiveness, but not with lymph node metastasis. Cancer Manag Res. 2018 May; 10:1005-1013. PMid:29760568 https://doi.org/10.2147/CMAR.S159583

[38] Bullock M, Ren Y, O'Neill C, et al. TERT promoter mutations are a major indicator of recurrence and death due to papillary thyroid carcinomas. Clin Endocrinol (Oxf). 2016 Aug; 85(2):283-90. PMid:26667986. https://doi.org/10.1111/cen.12999

[39] Liu R, Bishop J, Zhu G, et al. Mortality risk stratification by combining BRAF V600E and TERT promoter mutations in papillary thyroid 
cancer: genetic duet of BRAF and TERT promoter mutations in thyroid cancer mortality. JAMA Oncol. 2016 Sep 1. PMid:27581851. https://doi.org/10.1001/jamaoncol.2016.3288

[40] Jin L, Chen E, Dong S, et al. BRAF and TERT promoter mutations in the aggressiveness of papillary thyroid carcinoma: A study of 653 patients. Oncotarget. 2016 Apr; 7(14):18346-55. https: //doi.org/10.18632/oncotarget.7811

[41] Jin A, Xu J, Wang Y. The role of TERT promoter mutations in postoperative and preoperative diagnosis and prognosis in thyroid cancer. Medicine (Baltimore). 2018 Jul; 97(29): e11548. PMid:30024548. https://doi.org/10.1097/MD.0000000000011548
[42] Liu C, Liu Z, Chen T, et al. TERT promoter mutation and its association with clinicopathological features and prognosis of papillary thyroid cancer: A meta-analysis. Sci Rep. 2016 Nov; 6: 36990. PMid:27833153. https://doi.org/10.1038/srep36990z

[43] Moon S, Song YS, Kim YA, et al. Thyroid. 2017 May; 27(5):651-660. PMid:28181854. https ://doi .org/10.1089/thy.2016.0350

[44] Vuong HG, Altibi AM, Duong UNP, et al. Prognostic implication of BRAF and TERT promoter mutation combination in papillary thyroid carcinoma-A meta-analysis. Clin Endocrinol (Oxf). 2017 Nov: 87(5):411-417. PMid:28666074. https://doi .org/10.1111/ce n. 13413 